\title{
Prevalence and risk factors of childhood Asthma in El-Beyda city in Northeast of Libya
}

\author{
Marfoua. S. Ali ${ }^{1}$, Fareda. H. Mekal ${ }^{1}$, Rania. M. Taib ${ }^{2}$,Salema R.M Qowaider ${ }^{3}$ \\ ${ }^{1}$ Zoology Department, Faculty of Science, Omar El-Mokhtar University, El -Beyda-Libya. \\ ${ }^{2}$ Paediatric Department, Faculty of Medicine, Omar El-Mokhtar University, El -Beyda-Libya. \\ ${ }^{3}$ Microbiology and Immunology Department, Faculty of Medicine, Omar El-Mokhtar University, El-Beyda-Libya.
}

\begin{abstract}
Asthma is one of the most common chronic diseases in childhood. According to guidelines, a diagnosis of asthma should be confirmed using lung function testing in children aged $>6$ years. Previous studies indicate that asthma in children is probably over diagnosed. However, the extent has not previously been assessed. Our objective was to assess the extent and characteristics of confirmed and unconfirmed diagnoses of asthma in 290 children who were diagnosed by Central hospital as having asthma or who were treated as having asthma. Routine care registration data of children aged month to fourteen years who received a diagnosis of asthma or were treated as having asthma were analysed. Over diagnosis of childhood asthma is common in primary care, leading to unnecessary treatment, disease burden, and impact on quality of life. By the end of the study period, 140 (48.7\%) were $\leq 6$ years of age and 150 (51.3\%) were $>6-14$ years of age. In first group of patients, the first episode of wheezing occurred in the first six months of life about 14\%. In the sample as a whole, the prevalence of family history was high (50\% -60\%). The highest prevalence being in boys in the age group of 10-14 years (45.6\%) (46 girls and 36 boys). Conclusions: To our knowledge, the data we provide are the first to be reported on prevalence of asthma risk factors and lung function in this region, which seems to be crucial for improving management of asthmatic children.
\end{abstract}

Keywords: Asthma; children; diagnosis; guidelines; respiratory function tests; spirometry.

\section{Introduction}

Asthma is the most prevalent paediatric chronic disease and affects more than 300 million people worldwide [1]. The global prevalence of asthma and related symptoms has ranged between approximately 2 and $37 \%$ [2]. According to recent CDC data, asthma affects approximately $8.5 \%$ of the paediatric population in the U.S., or more than 7 million children [3]. It is a disease that has been observed to be more prevalent in developed countries with higher rates seen in Australia, UK, New Zealand [1], Chennai [4], India [5] and in Brazil [6]. In Nigeria, ranges from 7\% to $18 \%$ in the general population [7]. Prevalence of asthma has not been accurately estimated due to lack of population-based data, especially from less developed countries. Asthma is one of the most common chronic diseases in childhood, the prevalence of asthma in childhood is increasing. This is also the case with other allergy conditions, including eczema (atopic dermatitis), hay fever (allergic rhinitis), and food allergies [3]. Symptoms are often worse with exertion or during the night. Symptoms can also have a seasonal variation, which can be due to environmental allergies. Children with asthma often have a history of recurrent bronchitis or even a recurrent croup-like cough [3]. The diagnosis of asthma in children is often a purely clinical diagnosis. Improvement with a trial of asthma medications essentially confirms the diagnosis of asthma. If the child is old enough, they may undergo testing to aid in the diagnosis of asthma. Spirometry is one of a breathing test to measure lung function and children can generally start performing proper technique for this testing around 5 years of age. In younger children who cannot perform proper technique for lung function testing, the vast majority of younger children are diagnosed based on history alone. There is as yet no curative treatment for asthma; the primary goal of treatment is disease control. Asthma prevalence is increasing despite recent advances being made in its management [8\&9]. The present study was conducted in the Centre of El-Beyda, a city in the northeast region in Libya, El-Beyda reflects the characteristics of Mediterranean climate, which is hot and dry in summers and warm and rainy in winters and it is windy almost every day throughout the year. Our purpose was to present asthma in children and the characteristics and risk factors of the patients followed in the program of treatment. No study of this kind has previously been conducted in this region. 


\section{Material And Methods}

Patients: A group of 290 children with bronchial asthma (age:Weeks-14 years) obtained from Paediatric Allergy Clinic and Out-patients department at El-Beyda's Hospital, Libya, over a period of 5 years were included in the study. The list of analyzed allergic and respiratory diseases included diagnoses established during the child's lifetime by a physician and reported by subject's parents for asthma and spastic bronchitis. Spastic bronchitis is a traditional diagnosis of the region and is used to describe chronic or recurrent asthmatic symptoms such as wheezy bronchitis. Respiratory symptoms during their lives were also assessed by report. Several variables were considered as potential correlates of respiratory outcomes. Parental asthma, allergic rhinitis, eczema were separately defined by a report of a positive history of physician diagnosed disease by either the mother or father. Brest feeding, premature, height $(\mathrm{cm})$ and weight $(\mathrm{kg})$ were reported. Evaluation of health care utilization and morbidity was based on answers to questions regarding medication use for breathing, specialist or general practitioner visits for breathing conditions, completion of spirometry testing. A Spirometry is a device used for the evaluation of lung function with a spirometer. It is one of the simplest most common pulmonary function test. The peak expiratory flow (PEF), is a person's maximum speed of expiration, as measured with a peak flow meter, a small, hand-held device used to monitor a person's ability to breathe out air. (Spirometry was performed by HELIOS 401 Spirometer (Recorders and Medicare Systems, Chandigarh)). It measures the airflow through the bronchi and thus the degree of obstruction in the airways. After taking a deep breath a person forcefully breaths out in the spirometer as completely and forcefully as possible. PEF was measured in standing position with Wrights mini peak flow meter after the demonstration. Most children by five years of age can perform a spirometry [10\& 11]. Routine care registration data of children aged weeks-14 years who received a diagnosis of asthma or were treated as having asthma were analyzed.

\section{Results}

The study included 290 subjects almost equally distributed in all ages. Of those, $48.3 \%$ were aged 5 years or younger (few days), which included $65 \%$ boys and $35 \%$ girls. $10 \%$ of patients were premature, and most of them had been exclusively breastfed for at least 6 months. About $14 \%$ of the patients aged up from 5 years had a history of recurrent wheezing which had started early, before 6 months of age. Second group (51.7\%) were aged 6 years to 14 years, which included $47.4 \%$ boys and $52.6 \%$ girls (Table 1 ). The highest prevalence being in boys in the age group of 10-14 years (45.6\%) (46 girls and 36 boys). Positive family history with asthma were identified in 50\% and $60 \%$ of first and second groups respectively. The sinusitis were identified in 37 patients in young ages and 56 patients in second group of the cases. As well as dust allergy was identified in $15 \%$ in first group and $13.3 \%$ in second group. Of all patients, smoke sensitivity was reported around $6 \%$. However, nearly $3 \%$ of all cases were diagnosed with eczema. In only second group $(n=150)$ of the children diagnosed with asthma was the diagnosis confirmed with spirometry. Peak Expiratory Flow (PEF) measurement was carried. Children who had asthma-like symptoms or positive family history of asthma or physician-labeled asthma were subjected to spirometry and bronchodilator reversibility. Three readings were taken. The values were adjusted for gender and height. The reading for PEF were averaged (20 to 90\%). Less than $50 \%$ of the usual or normal peak flow readings: indicates a medical emergency. Severe airway narrowing may be occurring and immediate action needs to be taken. This would usually involve contacting a doctor or hospital. 80 to $100 \%$ of the usual or normal peak flow readings are clear: A peak flow reading in the green zone indicates that the asthma is under good control [12\&13]. On univariate analysis, the risk factors found to be with asthma were family history of asthma, seasonal cough, allergic rhinitis, dust allergy and smoke sensitivity.

Table 1. Patients followed in the Paediatric Allergy Clinic at El-Beyda's Hospital, by clinical characteristics and age group - El-Beyda from 2008 to 2015.

\begin{tabular}{|c|c|c|}
\hline \multirow[t]{2}{*}{ Characteristic } & \multicolumn{2}{|c|}{ Follow-up penitents } \\
\hline & $\leq 5$ years $(\mathrm{N}=140)$ & $>5$ years $(\mathrm{N}=150)$ \\
\hline Boys & $65 \%$ & $47.4 \%$ \\
\hline Girls & $35 \%$ & $52.6 \%$ \\
\hline Height & $20-100 \mathrm{~cm}$ & $160-105 \mathrm{~cm}$ \\
\hline Wight & $2-22 \mathrm{~kg}$ & $17-60 \mathrm{~kg}$ \\
\hline First episode before 6 months of age & $14 \%(24)$ & \\
\hline Exclusive breastfeeding & \multicolumn{2}{|c|}{$30 \%$} \\
\hline Family history & $50 \%$ & $60 \%$ \\
\hline Physician-diagnosed asthma & $10.7 \%(15)$ & $20.6 \%(31)$ \\
\hline Eczema & $3.5 \%(5)$ & $3.4 \%(5)$ \\
\hline Sinusitis & $26.4 \%(37)$ & $34 \%(51)$ \\
\hline Dust allergy & $15 \%(21)$ & $13.3 \%(20)$ \\
\hline Smoke sensitivity & $6.4 \%(9)$ & $6 \%(9)$ \\
\hline $\begin{array}{l}\text { Premature (born in seven months) } \\
\end{array}$ & \multicolumn{2}{|c|}{$10 \%$} \\
\hline Spirometry testing (Peak expiratory flow) PEF & Unable to do this test & $20 \%-90 \%$ \\
\hline
\end{tabular}




\section{Discussion}

With the increasing prevalence of asthma, numerous studies have looked at risk factors and ways to potentially prevent asthma. According to ISSAC study which compared the prevalence rates of asthma at 155 centres in 56 countries in children aged between 6-7 and 13-14 years [2]. This study was therefore, aimed to determined different risk factors that play roles to increase prevalence of asthma in Northeast of Libya. Routine care registration data of children aged days-14 years who received a diagnosis of asthma or were treated as having asthma at Paediatric Allergy Clinic and Out-patients department at El-Beyda's Hospital were analyzed. As can be seen in Table 1, gender distribution of asthma ever was in favor of boys, although current asthma prevalence was similar in both sex groups. In childhood, asthma affects more boys than girls for unknown reasons, but by the third decade, the prevalence becomes equal [1\&9], that agree with our study. When segregated by age, asthma was seen more in the age group of 10-14 years. This was similar to findings observed by Gupta et al [14]. The children aged up to 5 years followed in the program experienced symptom onset in the first year of life, and the first episode of wheezing occurred before 6 months of age, as reported by other studies [15\&16], and this probably reflect to the weak immune system beside positive family history. A high number of children in the two groups studied had severe from smoke sensitivity and dust allergy. From previous studies, exposure to cigarette smoke or dust have been identified as two of the most important risk factors for the development of wheezing in infants and asthma in older children [17\&18]. This study also agree with another study in west of Libya which reported association of childhood asthma and breastfeeding and other independent risk factors including expose to smoking [19], as well as agree with similar study in North Carolina [20]. At this point we can conclude that identifying these children and the risk factors leading to more severe asthma is of the utmost importance for public health [21]. Another finding worthy of note in this study was the number of children who had been born at seven month (10\%), which is identified as a risk factor for developing asthma later in life, especially if associated with a family history of asthma [22]. From our results, around $3 \%$ of among children have been diagnosis with eczema and sinusitis ( $26.4 \%$ \& $30 \%$ receptively in two groups of study). It is not fully understood why children develop asthma, although people with asthma often have a family history of asthma, eczema, allergies and allergic rhinitis. This data agree with another study which is estimated that approximately one in ten Australian children have asthma, eczema, allergies and allergic rhinitis [17]. In our study, a relationship was observed between family history and asthma (50\% and 60\%). This observation agree with number of studies that have shown an association between family history and asthma [23, 24, 25 and 26].

Other objective measures to help in the diagnosis of paediatric asthma include using a peak flow meter which can help to estimate lung function. In only the children diagnosed with asthma was the diagnosis confirmed with spirometry (range from $20 \%$ to $90 \%$ depending on age, weight and tall). Sometimes, testing for airway hyper responsiveness can help diagnosis asthma, again in older children capable of performing proper technique. Normal spirometry values are values at or above $80 \%$ to $85 \%$ of the predicted value for that measurement in a healthy child of similar age and characteristic [12\&13]. It is very important to recognize that a child can have poorly-controlled asthma despite completely normal lung function. Therefore, normal lung function does not preclude the diagnosis of asthma if a physician's clinical suspicion is high. Final point, ElBeyda reflects the characteristics of Mediterranean climate, however associations between the environment and asthma have been less consistent comparing with other factors which agree with finding by Brozek, et al [27]. The goal always remains to treat children with the least amount of medication that is effective. Thus, improving patients' and physicians' expectations of what can be achieved with asthma therapy may lead to improved overall asthma control.

\section{Conclusion}

Asthma is the most common reason for children being admitted to hospital, presenting to their doctor or hospital emergency department, the future directions on asthma research should focus on the mechanisms of the susceptibility and exaggerated response to lower respiratory tract infections. Information on characteristics of individual patients might be beneficial in strategies to prevent seasonal exacerbations, and should be evaluated in studies addressed to achieve a personalized approach to asthma. Finally, if your child's asthma is well managed, they should be able to lead a healthy active life.

\section{References}

[1] M. Masoli. D. Fabian, S. Holt and R. Beasley. Global Initiative for Asthma (GINA) Program. The global burden of asthma: Executive summary of the GINA Dissemination Committee report. Allergy. 59:2004, 469-478.

[2] The International Study of Asthma and Allergies in Childhood (ISAAC), Steering Committee. Worldwide Variations in the Prevalence of Asthma Symptoms: The International Study of Asthma and Allergies in Childhood (ISAAC). Euro Respiration Journal. 12:1989, 315-335.

[3] The Centers for Disease Control and Prevention (CDC), National guidelines. Asthma by consensus IAP respiratory chapter.2003, Pp 1-18.

[4] K.S. Sharma and R. Chopra. Indian Journal of Nursing. Respiratory Nursing. 8:2008, 42-44. 
[5] R. Pal, S. Dahal and S. Pal. Prevalence of bronchial asthma in Indian children. Indian Journal Community Medicine. 34:2009, 310316.

[6] M. Urrutia-Pereira, J. Avila and D. Solé. The Program for the Prevention of Childhood Asthma: a specialized care program for children with wheezing or asthma in Brazil. Journal Bras Pneumol. 42(1): 2016, $42-47$.

[7] O. O. Desalu, P. O. Oluboyo and A.K. Salami. The prevalence of bsronchial asthma among adults in Ilorin, Nigeria. African Journal Medical Science. 38:2009, 149-154.

[8] J.A. Saleh. Combination therapy in asthma: A review. Niger Journal Medicine.. 17:2008, 238- 243.

[9] A. O. Oni, G. E. Erhabor and E. E. Egbagbe. The prevalence, management and burden of asthma- a Nigerian study. Iran J Allergy Asthma Immunology. 9:2010, 35-41.

[10] A. J. Thomas and M. J. McIntosh. Are incentive spirometry intermittent positive pressure breathing, and deep breathing exercises effective in the prevention of post-operative pulmonary complications After abdominalsurgery?. Phys Therapy. 74(1):1994, 3-10.

[11] M. R. Miller, R. Crapo, J. Hankinson, V. Brusasco, F. Burgos and R. Casaburi R. General Considerations for lung function testing. Euro Respiration. Journal. 26:2006, 153-161.

[12] M. L. Levy, P.H. Quanjer, R. Booker, B. G. Cooper, S. Holmes and I. R. Small. Diagnostic spirometry in primary care. Primary Care Respiratory Journal. 18(3), 2009, 130-147.

[13] K. P. Patra. Focus on diagnosis: Spirometry. Pediatrics in Review. 33(10),2012, 469-472

[14] M. K. Gupta, B. S. Sharma and R. Chandel. Prevalence of asthma in urban school children in Jaipur, India. Pediatric Research. $70: 2011,517$

[15] J. A. Castro-Rodríguez, J. C. Holberg, A. L.Wright and F. D. Martinez. A clinical index to define risk of asthma in young children with recurrent wheezing. American Journal of Respiratory and Critical Care Medicine. 162(4 Pt 1):2000, 1403-1406.

[16] M. U. Pereira, J. C. Ivancevich, D. Solé and J. Mallol. Prevalence of recurrent wheezing in infants in a poor urban city in South Brazil. World Allergy Organs Journal. 6(Suppl 1):2013, 43.

[17] J. K. Peat, E. Tovey. B. G. Toelle, M. M. Haby. E. J. Gray. A. Mahmic and A. H. Woolcock. A.H. House dust mite allergens. A major risk factor for childhood asthma in Australia. American Journal of Respiratory and Critical Care Medicine. 153:1; 1996, $141-146$.

[18] H. Burke, J. Leonardi-Bee, A. Hasmim, H. Pine-Abata, Y. Chen and D. G. Cook. Prenatal and passive smoke exposure and incidence of asthma and wheeze: systematic review and meta-analysis. Pediatrics. 129 (4):2012, 735-44.

[19] I. O. Aboshaala. The association of childhood asthma and breastfeeding and other independent risk factory. Al-satil, A Refereed Academic journal. 9:12:2015, 21-33.

[20] H. Herrick. The Association of Breastfeeding and Childhood Asthma: Results from the 2005 North Carolina Child Health. Assessment and Monitoring Program, State Center for Health Statistics North Carolina Division of Public Health.152:2007, 1-9.

[21] G. Ng Man Kwong, A. Proctor, C. Billings, R. Duggan, C. Das and M. K. Whyte. Increasing prevalence of asthma diagnosis and symptoms in children is confined to mild symptoms. Thorax.56:2001, 312-314.

[22] M, Weng. W. A. Walker. The role of gut microbiota in programming the immune phenotype. Journal Development Origan Health Dis. 4(3):2013, 203-214

[23] H. Paramesh. Epidemiology of asthma in India. Indian Journal Pediatrics. 69:2002, 309-312.

[24] A. Jain, H. Vinod Bhat and D. Acharya. Prevalence of bronchial asthma in rural Indian children: A cross sectional study from South India. Indian Journal Pediatrics. 77:2010, 31-35.

[25] U. A. Qureshi, S. Bilques, I. Haq, M. S. Khan, M. A. Qurieshi and U. A. Qureshi. Epidemiology of bronchial asthma in school children (10-16 years) in Srinagar. Lung India. 33(2):2016, 167-173.

[26] L. Akker, K. van Luijn and T. Verheij. Overdiagnosis of asthma in children in primary care: a retrospective analysis. British Journal General Practical. 66(644):2016, 152-157.

[27] G. Brozek, J. Lawson, A. Shpakou, O. Fedortsiv, L. Hryshchuk, D. Rennie and J. Zejda. Childhood asthma prevalence and risk factors in three Eastern European countries - the Belarus, Ukraine, Poland Asthma Study (BUPAS): an international prevalence study. BMC Pulmonary Medicine. 16:2016, 1-11. 